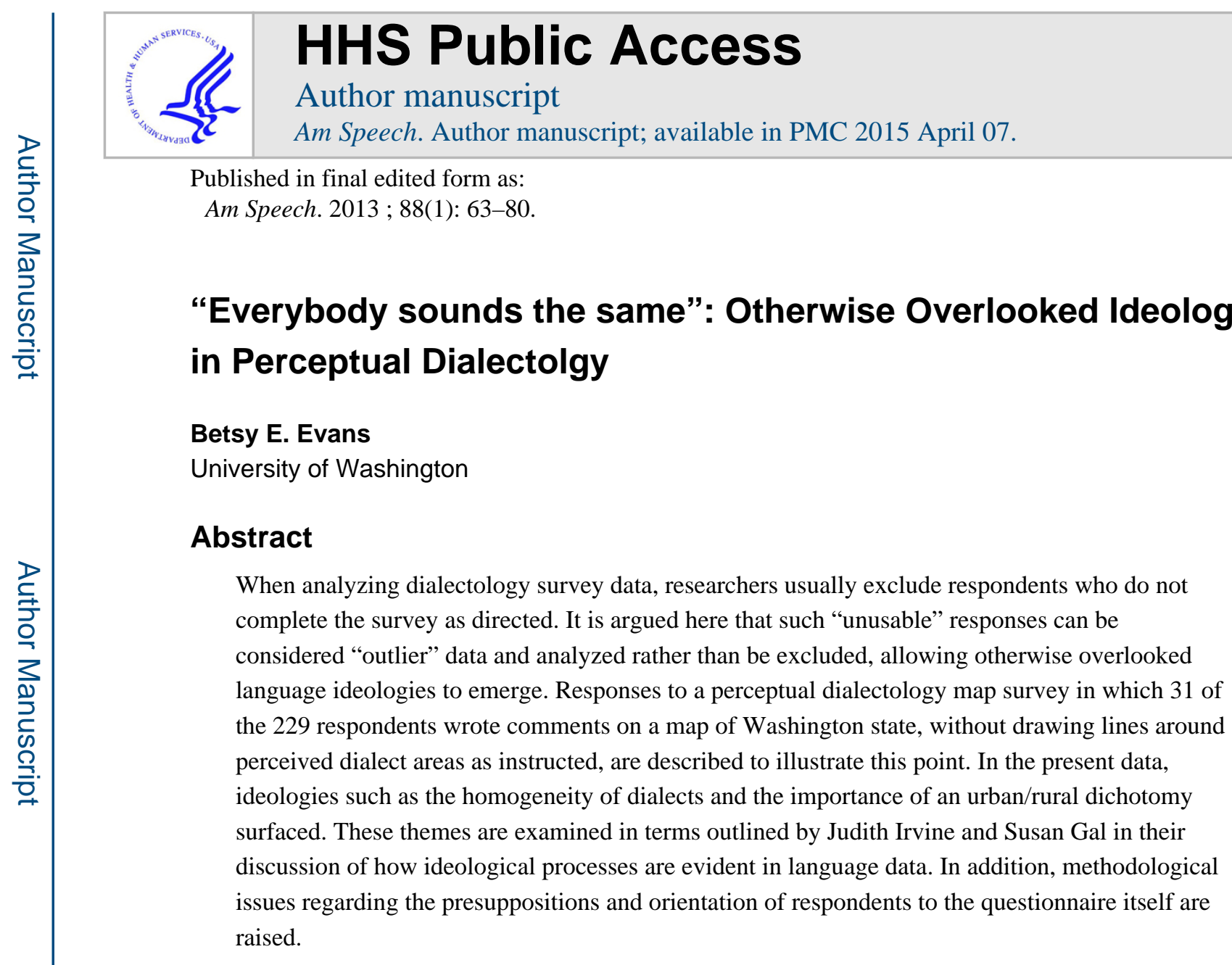

When analyzing survey data, researchers usually exclude respondents who do not complete the survey as directed, but such supposedly unusable responses can be considered outliers rather than useless. To be clear, not just any sort of incomplete response lends itself to analysis, but rather a consistent type of noncompliance to a specific survey task. Here, I suggest that the "unusable" data can provide information about language ideology. The data described below come from responses to a perceptual dialectology survey that asks respondents what linguistic differences they perceive in their region (described more fully below). If respondents don't indicate some difference(s), then what is the researcher to do with their survey responses? A response that indicates "there is no difference" is, in fact, a response, although not the type of response sought by the survey task or normally reported in perceptual dialect surveys (e.g., Long 1999, 179). Nevertheless, they can represent respondents' perceptions about language, as well as the task, and can even suggest new directions for research.

Specifically, this article describes a subset of data from a larger project investigating the perceptions Washington residents have about English spoken in their state (Evans 2010, 2011a, 2011b). That project used a perceptual dialectology map survey instrument (Preston and Howe 1987) and asked respondents to mark on the map the places where they believe

Copyright 2013 by the American Dialect Society

An earlier version of this article, titled “'Everybody Sounds the Same': 'Marginal' Data in Perceptual Dialectology," was presented at the 2012 annual meeting of the American Dialect Society in Portland, Oregon, January 5-7. 
"people's English sounds different" and to label them if possible. Of the 229 respondents who completed the survey, 178 completed the task as directed. Some respondents didn't complete the task; instead, they filled out the demographic information and left the rest of the form blank (20/229). Others apparently rejected "drawing lines around places where people speak differently" but instead wrote comments on the map. This article considers the 31 responses consisting of comments written on the maps without drawn lines. These responses are valuable in spite of their small number because language ideologies emerge even in only partially completed surveys.

\section{PERCEPTUAL DIALECTOLOGY}

Perceptual dialectology (or "folk dialectology") is the study of what nonlinguists' believe about language variation-for example, how language does/does not vary, how language should/should not be used, what social or geographic categories are associated with variation. A sizeable body of research on lay perceptions of language (e.g., Lambert et al. 1960; Giles 1970; Giles and Ryan 1982; Niedzielski and Preston 2003) demonstrates the pervasive and intense nature of speaker attitudes to varieties of language, "a person's evaluation of any psychological object" (Ajzen and Fishbein 1980, 27). So, while linguists can study shared linguistic production features, the affective dimension of those features is also important for understanding and describing a language variety, as well as the community using those features.

Preston (1981) borrowed the "mental mapping" technique for perceptual dialectology from cultural geography (Gould and White 1974) and developed a method for determining perceived regional speech boundaries, which included questions about degree of difference from the respondent's home area and correctness and pleasantness of speech in different regions. This method involved asking respondents to draw dialect boundaries on a map of the United States in addition to asking the respondents to rank the 50 states on affective qualities. In this way, subjective judgments of the spatial distribution and affective values of speech varieties could be measured quantitatively. After his initial study in Hawaii, Preston repeated these methods in other states, and several other scholars have since carried out similar surveys of U.S. residents' perceptions of U.S. English (e.g., Hartley 1999, 2005; Fought 2002; Fridland and Bartlett 2006).

In addition to scales of correctness and pleasantness, Preston (1981) asked respondents to judge the "degree of difference" between regional varieties. Weijnen (1999), Rensink (1999), Grootaers (1999), and Sibata (1999), for example, explored the "degree of difference" respondents felt existed between their home regions and those nearby. The present research asked respondents to draw on a map of the state of Washington "places where you think people's English sounds different. Next, write down what you'd call that way of talking, if you can think if a label for it" (see figure 1). ${ }^{1}$ The instruction to draw lines around where respondents believe English "sounds different" follows from previous research and is intended to encourage respondents to identify linguistic variation without

\footnotetext{
${ }^{1}$ The present study, following the lead of recent perceptual dialectology research that used only regional or single state maps (e.g., Benson 2003; Bucholtz et al. 2007; Cramer 2010), narrowed the geographical focus to the residents' home state rather than presenting respondents with a map of the entire United States.
} 
prompting them with the term "dialect." The term "dialect" has been found to be confusing and loaded for nonlinguists (Wolfram and Schilling-Estes 1998; Niedzielski and Preston 2003).

The present data are drawn from the 31 respondents who did not draw on their maps in the Washington project mentioned above. These outlier data may expose some of the underlying frameworks that respondents deploy when evaluating language variation. "Typical" responses to the task prompt suggest that respondents have accepted the prompt's presuppositions: (1) there are identifiable linguistic differences in the geographic area being queried; (2) lay people are aware of those linguistic differences; (3) lay people can identify those linguistic differences; and (4) lay people can associate linguistic differences with geographic locations. Perceptual dialectology research (such as that discussed above) has shown that these presuppositions hold true for many respondents, but not all (see Preston 1996 for a detailed taxonomy of folk linguistic awareness). The outliers here sometimes do challenge these presuppositions and thus give insight into aspects of respondents' positioning in relation to the prompt. The majority of the respondents (178/229) completed the task, and very few respondents indicated "I don't know," suggesting that they did not object to or were unclear about the task/prompt.

Because the main goal of the task is to ascertain respondents' spatial associations with linguistic difference, if the respondents' perceptions of difference have no spatial correlates (e.g., they perceive only social class differences), they cannot draw lines on the map to represent that difference. For example, the response from a 25-year-old male from Wenatchee (east central Wash.), who indicated on his map, "They all sound alike" (figure 1), thus obviates any lines. It does not seem warranted, however, to amend the data collection technique since the majority of the respondents seem comfortable with the task's presuppositions, although Tamasi (2010) provides an alternative method for collecting spatial perceptions of language. The main point here is that an answer such as that in figure 1 usually would be excluded from an analysis of a map task data set, yet it does present a perspective on language variation. Perhaps "nonconforming" data should be analyzed rather than "thrown out."

With regard to labels, some respondents lack the ability to describe linguistic differences, either linguistically or socially (Preston 1996), which inhibits their ability to produce labels as requested in the task. This effect is evident in the response from a 21-year-old male from Seattle who wrote on his map, "For the most part I feel all Washingtonians sound the same. Near Spokane, however, their [sic] seems to be a slightly different dialect but I don't know how to describe it." He could have circled the Spokane region on his map, but he did not. Caution is required when speculating on why respondents did or did not draw lines on their maps. A respondent's cognitive framework, influences, and motivations are not known to the researcher in a survey context; therefore, it is important to understand that such data are subjective, a perpetual limitation of both qualitative and quantitative research. Results to open-ended survey tasks inherently provide information that may not correspond to the researcher's intentions or may not reflect the respondent's "true" beliefs. Researchers can mitigate this (and other) limitations only through careful design of the survey and 
responsible analysis and interpretation of the results. Nevertheless, we should continue studying attitudes about language despite the problems they pose to research methods.

\section{WHY CONSIDER OUTLIERS?}

Variationist sociolinguists often exclude outlier data from analysis because they are unrepresentative. Nevertheless, sociolinguists have demonstrated the utility in considering outlier respondents. Britain (2003) specifically highlights data from outliers in his own and others' research. He describes two outlier speakers in his data from the Fens in eastern England who are linguistically unlike their peers in their usage of community linguistic "norms"; they deploy specific linguistic differences to negotiate and manage their sociogeographic isolation in the Fens. Britain demonstrates that examination of such outliers is a critical component of exploring language variation and has a place even in quantitativeoriented research.

Similarly, Johnstone (1996) demonstrates the importance of exploring individual behavior in sociolinguistic research. Through case studies of individuals, she describes and highlights the significance of inter- and intraspeaker variation. For example, she describes story-telling strategies used by two very different speakers that demonstrate how they use linguistic resources to create their own voice. Using examples like these, she proposes that research oriented to aggregating data leaves individual behavior unobserved. That is, aggregated results may hide as much as they reveal in so far as the variety among individuals and their distinctive profiles are not always apparent when respondents are evaluated as a group. Moreover, she suggests that outliers' behavior can be considered as theoretically important because close inspection of individual language use exposes the possibilities for creativity and individuality in language use. This sort of exploration of the individual has recently become an important theme in sociolinguistics (e.g., Eckert 2004; Coupland 2007).

Although these scholars have considered a different type of data derived from outliers (e.g., the production of linguistic variables) from the type explored here (metalinguistic commentary), the main point is that they share an emphasis on exploring data from "the overlooked" and how such data can contribute to our understanding of perceptions of language use.

\section{LANGUAGE IDEOLOGY}

The metalinguistic comments described below are examined in terms of the attitudes and ideologies they demonstrate. The relationship between language ideology and language attitude is a very complicated one, and there is considerable overlap of usage of the two terms and their definitions in language attitudes research. A full discussion of that issue isn't possible here, but there have been fruitful scholarly discussions of it elsewhere (e.g., Silverstein 1979; Woolard and Schieffelin 1994; Schieffelin, Woolard, and Kroskrity 1998; Milroy 2004; Eagleton 2007; Dyers and Abongdia 2010). For clarity in the present discussion, specific definitions of each are adopted, but other definitions are also plausible. First, an attitude is a reaction to an object; the object in this case is some aspect of language, as defined by Ajzen and Fishbein (1980, 27). Second, what is intended by ideology here is described by Irvine $(1989,255)$ as "the cultural (or subcultural) system of ideas about social 
and linguistic relationships, together with their loading of moral and political interests." Thus, language ideology is considered to be a group's shared ideas about the relationship between linguistic and sociocultural features (Dijk 1998, 9). Further, Wassink and Dyer (2004) suggest that language ideology and language attitudes are distinct entities but consider language ideology to be a mediating process for an affective reaction. That is to say, an attitude/reaction to an object is informed and formulated with the assistance of the "system of ideas" of the respondent.

With regard to ideology and language differentiation, Irvine and Gal $(2000,37)$ describe processes through which "people construct ideological representations of linguistic differences." Irvine and Gal observe the processes that seem to inform the construction of ideologies, where they come from, and how they can be described at a metalevel. Processes of language differentiation are particularly relevant here since the present research specifically asks respondents about where "difference" exists. Irvine and Gal identify three processes in particular: iconization, fractal recursivity, and erasure. Briefly, iconization is the process by which "[1]inguistic features that index social groups or activities appear to be iconic representations of them" (37); fractal recursivity is the process by which "an opposition, salient at some level of relationship, [is projected] onto some other level"; and erasure is the process which "renders some persons or activities (or sociolinguistic phenomena) invisible" (38). These processes are evident in the results described in detail below. We can make sense of outlier responses on the terms Irvine and Gal identify. In the next section, the data are described to illustrate the richness and utility of outlier data.

\section{DATA}

Participants who did not draw lines on their maps were fairly evenly balanced between males $(n=14)$ and females $(n=17)$. More of these respondents were from western Washington $(n=22)$ than from eastern $(n=9)$. The average age of this group of respondents is 33 , slightly older than the average age of respondents who did draw lines (26).

A content analysis (Bauer 2002) of the comments from all 31 respondents who did not draw lines on their map exposes patterns in their responses. Following Garrett, Williams, and Evans (2005), I examined each response and grouped similar comments to reveal any emerging themes. If a respondent wrote down more than one word or phrase that represented different categories, each one was counted as a separate answer. So a comment such as "Washington has a fairly neutral accent, but outside of the metropolitan areas (specifically in the East) you might be able to catch a slight drawl" would be counted as two comments: "WA has a neutral accent" and "eastern WA has a drawl." While this method of analysis of keywords does allow for some respondents' opinions to be overrepresented (e.g., one respondent gives more labels than others), it prevents having to choose among a single respondent's answers. The content analysis resulted in five categories (see table 1): "there are no differences" ( $n=19)$, "differences are urban vs. rural" $(n=10)$, "differences aren't geographic" ( $n=8)$, "I don't know" $(n=2)$, and uncategorizable $(n=2)$. These categories (excepting uncategorizable) are described below. 


\section{THERE ARE NO DIFFERENCES IN WASHINGTON $(n=19)$}

The majority of comments asserted that there are no differences in the English spoken in Washington (table 1). The comments range from quite confident assertions to more reticent statements. For example, a 75-year-old respondent from Walla Walla quite emphatically claims that there are no differences in the way people in Washington sound (figure 2): "NONE! I don't find any different [sic] in speech EAST or WEST." On the other hand, a 42-year-old male from Entiat (east central Wash.), makes a more apologetic proclamation, indicating, "I'm sorry to say I have not noticed a linguistic change anywhere in the state." These responses reflect a belief in homogeneity of English in Washington. Irvine and Gal $(2000,76)$ suggest that the belief in homogeneity, or ignorance of language differentiation (i.e., variation such as dialects, registers, and even languages), suggests a process of "erasure" and is so persistent that it exists even among language scholars. They identify "erasure" (37) as one of the "semiotic processes" by which "a social group or a language may be imagined as homogeneous, its internal variation disregarded" (38), which "renders some persons or activities (or sociolinguistic phenomena) invisible" (38)—elements that do not fit an individual's ideological scheme are disregarded. Erasure is a process of essentialization. Some essentializing processes result in the perception of one's own group as heterogeneous and the out-group, or "other," as homogenous, a social interpretation known as the out-group homogeneity effect (e.g., Judd and Park 1988). The present respondents, however, seem to perceive their English as homogenous and perhaps view heterogeneity as something that exists elsewhere. For example, one respondent wrote on the front of his map, "In my opinion, people born and raised in Washington do not have accents. The ones I hear are from other parts of the U.S. or other countries." Perhaps the "erasure" of linguistic variation in Washington for these respondents is the result of a lack of linguistic caricature in Washington at this point in time; that is, the features unique to Washington are (as yet) mostly unnoticed for these respondents. As Preston (1996, 63) notes, "Linguistic awareness is enhanced when the object is a folk artifact." Thus, respondents assume there aren't any distinguishing characteristics of English in Washington because there is no strong linguistic or social stereotype of Washington available for them to draw on. Washington has received positive ratings for pleasantness and correctness in studies of perceptual dialect maps collected across the United States (e.g., Preston 1983, 73; Hartley 2005; Fridland and Bartlett 2006), suggesting that outsiders (i.e., non-Washington residents) also perceive Washington as unremarkable with regard to language difference.

It is worth noting, however, that the majority of the respondents in the larger study did, in fact, report that they perceive difference in the English spoken in Washington (Evans 2010, 2011a, 2011b), thus placing these respondents solidly in the minority in this perception.

\section{DIFFERENCES ARE URBAN VS. RURAL $(n=10)$}

Other comments suggest that the key differences in the English spoken in Washington are the result of differences between urban and rural populations (see table 1). For example, a 20-year-old female from Snohomish (western Wash.) wrote on her map, "not specific areas, but more based on city size. People (some, not all) from smaller towns are more relaxed when they speak, while some people from larger cities are more rushed and uptight." The responses in this category are fairly neutral in evaluation, such as "Urban areas are different 
from the country, mostly in relation to lifestyle" (19-year-old male from Wenatchee) or "Rural English can also take on an embraced Appalachian or Texas sound" (22-year-old female from Seattle). A few respondents associated rural areas with "Southern" speech but were, again, fairly neutral about that assignation. For example, an 18-year-old male from Vashon Island (western Wash.) wrote, "Washington has a fairly neutral accent, but outside of the metropolitan areas (specifically in the East) you might be able to catch a slight drawl." Another respondent associated positive attributes to rural speech on her map: "I've lived in Centralia/Lewis County for a few years, a lot of people had characteristics of southern dialect in their speech fixn instead of fixing. I found the speech friendly and welcoming!" (21-year-old female from Olympia).

These impressions of the difference between rural and urban speech could be viewed as an example of fractal recursivity. Irvine and $\operatorname{Gal}(2000,38)$ describe the process of fractal recursivity as occurring when "the dichotomizing and partitioning process that was involved in some understood opposition (between groups or linguistic varieties, for example) recurs at other levels." In the present data, the perception of the cultural differences between rural and urban life (e.g., rural $=$ relaxed, urban $=$ rushed) are imposed onto the language used in those regions. As Irvine and Gal state, this reassignment of stereotypes "provide[s] actors with the discursive or cultural resources to claim and thus attempt to create shifting 'communities,' identities, selves, and roles, at different levels of contrast, within a cultural field" (38).

Fridland and Bartlett (2006) also found the urban/rural distinction significant in their respondents' intraregional distinctions. They reported ratings of U.S. English by speakers in Memphis, Tennessee, and found that while Memphians rated their region (the U.S. south) as less correct than other U.S. regions, they rated their own state as more correct and pleasant than more rural neighboring states within the Southern region. Fridland and Bartlett suggest that Memphians' downgraded their rural neighbors and upgraded themselves because of Memphis's position in the region as an urban center and a self-perceived higher status associated with urban centers.

These responses and those Fridland and Bartlett (2006) received indicate that the urban/rural distinction is a socially salient one that influences respondents' perceptions of language used in those areas. The importance of the urban/rural distinction was also present among the respondents who fully completed the map survey. Figure 3 is a composite map of all the respondents who did complete the map survey $(n=178)$. The high percentage of respondents who circled urban areas all over the state suggests the urban/rural distinction is important for these respondents as well. The areas reflect the population distribution in Washington fairly accurately when compared to a map of urban/rural areas based on U.S. census data (see figure 4). Thus, perceptions of urban/rural distinctions in this subset of data are consistent with the larger data set.

While urban/rural differences seem to be noticed by nonlinguists, exploration of linguistic variation in rural contexts has received less attention since the move away from traditional dialectology and the shift to the study of urban areas, accelerated by Labov (1966). Yet Britain (2009) argues that the patterns of variation sociolinguists seek are not unique in urban areas: "The very same cultural, economic, social and political processes and conflicts 
can affect rural areas as affect urban [areas]" (238). The present data suggest that there are still important sociocultural and linguistic reasons for conducting research in rural areas as well as urban ones and that sociolinguists should not ignore rural populations.

\section{DIFFERENCES AREN'T GEOGRAPHIC $(n=8)$}

A few respondents indicated that linguistic differences in Washington are due to nongeographic factors, such as education or lifestyle. As described above, the perceptual dialectology map task is problematic for respondents who do not perceive the linguistic differences they notice as having spatial characteristics or if they reject the notion that geography should be used to define speech. Some respondents navigate this issue by indicating that space is not relevant for them. For example, a female respondent from western Washington indicated, "I am having difficulty with this survey because Washington is a rather hodge-podge area when it comes to dialects. I can not [sic] differentiate accents based on area, both due to lack of exposure and to an open mind." Some seem to reject a perceived suggestion of the prompt (but, of course, not intended) that people should be categorized by their speech characteristics. For example, a 20 -year-old male from western Washington wrote: "I do not notice differences on a regional level. I have traveled around Washington and every accent I hear is on an individual basis. I've heard southern accent [sic] and hispanic accent [sic] all over Washington: Olympia, Bellingham, Spokane, Pullman, Aberdeen, Vancouver, and Forks." Another such example was given by an 18year-old female from Seattle: "I don't know if it's geographic location that makes the difference, but rather a choice of which culture to embrace."

Bucholtz et al. (2008) found similar "relativistic" responses that seemed to challenge their questionnaire's request for respondents to indicate "where people speak the best" or "worst" English in California. They also found that those "challenging" responses were largely from ethnic minority respondents, who they suggest were resisting language ideologies of "best/ worst" language varieties by subverting the question. It is frustratingly difficult to ascertain motivations for such answers. They may be due to independent thinking or attempts to provide whatever respondents believe to be the socially most acceptable answer.

"Relativistic" answers to perceptual dialectology tasks should be explored further to determine what they reveal about the respondents and the task itself.

Another perception of linguistic differentiation not a result of geography, but rather the perceived presence of nonnative English speakers, was suggested by a few respondents, such as a 21-year-old female from Whidbey Island (western Wash.), who noted on her questionnaire, "Aside from nonnative english [sic] speakers, Washingtonians have few/no distinctions." A 32-year-old male from Wenatchee provides another such example: "I've never noticed any differences-except spanish $[$ sic $]$ accent, which randomly [sic] distributed in Washington."

A few respondents noted linguistic differentiation associated with groups not tied to geography, such as social class: "I think most of educated Washington sounds about the same" (20-year-old female from central Wash.); or race: "Although, most of the accents relate to race or speach [sic] impediments" (18-year-old male from Vashon Island, western Wash.). While these kinds of perceptions are few in number here, they reflect discourses 
frequently found in perceptual dialectology research (Niedzielski and Preston 2003) and were also present in the larger data set in the form of labels such as "ghetto," "rednecks," and "educated words wealthy."

These respondents use social groups to articulate the linguistic difference they are asked to identify. Thus, "Hispanic," "foreigner," "educated," and the like stand in for a description of that difference; the social group identified is linked to a language feature. There are two things to note here. First, this is a kind of iconization, a process by which "[1]inguistic features that index social groups or activities appear to be iconic representations of them, as if a linguistic feature somehow depicted or displayed a social group's inherent nature or essence" (Irvine and Gal 2000, 37). This includes the iconization of broader "linguistic features," such as multilingualism or perceived purity of a language (Irvine and Gal 2000, 55). Second, the kinds of social groups identified are consistent with established sociolinguistic variables of class, ethnicity, nonnative English speakers, and marked identity categories. In a sense, this indicates a rejection of the variable of place by respondents and reframes linguistic difference as a result of something else. It is a mode of resistant compliance, in so far as the informants provide information in more or less the requested terms, but in ways that question the primacy of the primary category here-place.

\section{DON'T KNOW $(n=2)$}

Only two respondents wrote that they couldn't answer the question. An 18-year-old female from Seattle gave an "I don't know" answer: "Really have stayed in Seattle most of the time." Another respondent gave a similar answer, indicating "only lived in one town" (19year-old female from north central Wash.). The small number of "I don't know" answers seems to reflect the lack of inhibition of respondents to provide their perceptions of language around their state and nation.

\section{CONCLUSION}

Follow-up interviews would certainly aid in interpreting responses to the map survey that consist of comments but do not provide shapes on the maps. Nevertheless, if we analyze these "unusable" data rather than exclude them, they may serve to help refine future questionnaires about linguistic perceptions, help confirm analyses from the larger data set, and uncover otherwise overlooked language ideologies. In spite of the small set reported here, there do seem to be some patterns worth noting.

First, the majority of the comments indicated that there are no differences in the English spoken in Washington, suggesting a belief that English is homogenous in Washington. This perception seems to reflect a semiotic process of erasure. If, as in previous studies, these data had been excluded, this language ideology would have been overlooked. This notion of homogeneity among Washingtonians should be further investigated to determine why linguistic differences in Washington are unnoticed (or ignored) by some residents and whether this perception is unique to Washingtonians and applies more to Washington than to other states. 
Other trends in the responses suggest perceptions that differences in English in Washington are due to a distinction respondents make between urban and rural lifestyles. This distinction of ideological perceptions of lifestyle applied to language suggests a process of fractal recursivity and is consistent with trends in the larger data set. This trend in the data also points to the importance of urban/rural distinctions, a distinction itself that has been overlooked by many in sociolinguistics.

Some respondents indicated that difference in English in Washington is not related to geography by suggesting that they didn't wish to categorize speakers, while others indicated the relevant categories aren't geographic but related to other factors, such as social class or one's status as a nonnative English speaker. These sorts of perceptions suggest the iconization of ideological beliefs about social class and language and are typical of metalinguistic commentary about language (Niedzielski and Preston 2003, 233-34). Such perceptions were also found in the larger data set.

Perceptions held by these Washingtonians form an integral part of the description of English in Washington. Metalinguistic commentary reflects the social discourses salient for them and, as such, demonstrate that they should not be excluded from analysis. Paying attention to outliers has a number of advantages. It allows some insight into the orientation of respondents to the questionnaire itself and, as a direct result of this, indicates their ideologies about language, over and above any information about their attitudes to language variation in Washington. Moreover, these outlying responses are also consistent with routine ideological processes. Resistance of the ideology offered by the questionnaire (that linguistic differentiation is salient) may appear to disturb the aims of the research. However, the responses provide an important reminder of the ideologies inherent in research questionnaires as well as the variation of language ideologies in the respondent community. Far from being "unusable," such data are rich and valuable.

\section{Acknowledgments}

I am grateful to Matt Dunbar of the University of Washington Center for the Studies of Demography and Ecology for his consultation and production on the maps and also to the anonymous reviewers and Annabelle Mooney for their invaluable comments.

\section{REFERENCES}

Ajzen, Icek; Fishbein, Martin. Understanding Attitudes and Predicting Social Behavior. Englewood Cliffs, N.J.: Prentice-Hall; 1980.

Benson, Erica J. Folk Linguistic Perceptions and the Mapping of Dialect Boundaries. American Speech. 2003; 78.3:307-330.

Britain, David. Exploring the Importance of the Outlier in Sociolinguistic Dialectology. In: Britain, David; Cheshire, Jenny, editors. Social Dialectology: In Honour of Peter Trudgill. Amsterdam: Benjamins; 2003. p. 191-208.

Britain, David. 'Big Bright Lights' versus 'Green and Pleasant Land'?: The Unhelpful Dichotomy of 'Urban' versus 'Rural' in Dialectology. In: Al-Wer, Enam; De Jong, Rudolf, editors. Arabic Dialectology: In Honour of Clive Holes on the Occasion of His Sixtieth Birthday. Leiden: Brill; 2009. p. 223-247.

Bucholtz, Mary; Bermudez, Nancy; Fung, Victor; Edwards, Lisa; Vargas, Rosalva. Hella Nor Cal or Totally So Cal? The Perceptual Dialectology of California. Journal of English Linguistics. 2007; 35.4:325-352. 
Bucholtz, Mary; Bermudez, Nancy; Fung, Victor; Vargas, Rosalva; Edwards, Lisa. The Normative North and the Stigmatized South: Ideology and Methodology in the Perceptual Dialectology of California. Journal of English Linguistics. 2008; 36.1:62-87.

Coupland, Nikolas. Style: Language Variation and Identity. Cambridge: Cambridge University Press; 2007.

Cramer, Jennifer. Ph.D. diss. University of Illinois at Urbana-Champaign; 2010. The Effect of Borders on the Linguistic Production and Perception of Regional Identity in Louisville, Kentucky.

Dijk, Teun A. van Ideology: A Multidisciplinary Approach. London: Sage; 1998.

Dyers, Charlyn; Abongdia, Jane-Francis. An Exploration of the Relationship between Language Attitudes and Ideologies in a Study of Francophone Students of English in Cameroon. Journal of Multilingual and Multicultural Development. 2010; 31.2:119-134.

Eagleton, Terry. Ideology: An Introduction. New ed.. London: Verso; 2007.

Eckert, Penelope. The Meaning of Style. In: Chiang, Wai Fong; Chun, Elaine; Mahalingappa, Laura; Mehus, Siri, editors. Proceedings of the Eleventh Annual Symposium about Language and Society; 2004. p. 41-53.Texas Linguistics Forum 47.

Evans, Betsy. Seattle to Spokane: Mapping Perceptions of English in Washington State. Paper presented at the 39th annual meeting on New Ways of Analyzing Variation (NWAV 39); San Antonio, Texas. Nov. 4-6; 2010.

Evans, Betsy. 'Seattletonian' to 'Faux Hick': Perceptions of English in Washington State. American Speech. 2011a; 86.4:383-414.

Evans, Betsy. Seattle to Spokane: Mapping Perceptions of English in Washington State. Project website. $2011 \mathrm{~b}$ http://depts.washington.edu/folkling/.

Fought, Carmen. California Student's Perceptions of, You Know, Regions and Dialects?. In: Long, Daniel; Preston, Dennis R., editors. Handbook of Perceptual Dialectology. Vol. 2. Amsterdam: Benjamins; 2002. p. 113-134.

Fridland, Valerie; Bartlett, Kathryn. Correctness, Pleasantness, and Degree of Difference Ratings across Regions. American Speech. 2006; 81.4:358-386.

Garrett, Peter; Williams, Angie; Evans, Betsy. Accessing Social Meanings: Values of Keywords, Values in Keywords. Acta Linguistica Hafniensia. 2005; 37:37-54.

Giles, Howard. Evaluative Reactions to Accents. Educational Review. 1970; 22.3:211-227.

Giles, Howard; Ryan, Ellen Bouchard. Prolegomena for Developing a Social Psychological Theory of Language Attitudes. In: Ryan, Ellen Bouchard; Giles, Howard, editors. Attitudes towards Language Variation: Social and Applied Contexts. London: Arnold; 1982. p. 208-223.

Gould, Peter; White, Rodney. Mental Maps. Harmondsworth, U.K.: Penguin; 1974.

Grootaers, Willem A. Kuiper, LawrenceThe Discussion Surrounding the Subjective Boundaries of Dialects. Orbis. 1999; 13(1964):380-398. In Preston 1999, 115-29. Translation of "La Discussion Autor des Frontières Dialectales Subjectives,".

Hartley, Laura C. A View from the West: Perceptions of U.S. Dialects by Oregon Residents. Preston. 1999:315-332. 1999.

Hartley, Laura C. The Consequences of Conflicting Stereotypes: Bostonian Perceptions of U.S. Dialects. American Speech. 2005; 80.4:388-405.

Irvine, Judith T. When Talk Isn't Cheap: Language and Political Economy. American Ethnologist. 1989; 16.2:248-267.

Irvine, Judith T.; Gal, Susan. Language Ideology and Linguistic Differentiation. In: Kroskrity, Paul V., editor. Regimes of Language: Ideologies, Polities, and Identities. Santa Fe, N.M.: School of American Research Press; 2000. p. 35-83.

Johnstone, Barbara. The Linguistic Individual: Self-Expression in Language and Linguistics. New York: Oxford University Press; 1996.

Judd, Charles M.; Park, Bernadette. Out-Group Homogeneity: Judgments of Variability at the Individual and Group Levels. Journal of Personality and Social Psychology. 1988; 54.5:778-788.

Labov, William. The Social Stratification of English in New York City. Washington, D.C.: Center for Applied Linguistics; 1966. 
Lambert WE, Hodgson RC, Gardner RC, Fillenbaum S. Evaluations Reactions to Spoken Languages. Journal of Abnormal and Social Psychology. 1960; 60.1:44-51. [PubMed: 14413611]

Long, Daniel. Geographical Perceptions of Japanese Dialect Regions. Preston. 1999:177-198. 1999.

Milroy, Lesley. Language Ideologies and Linguistic Change. In: Fought, Carmen, editor. Sociolinguistic Variation: Critical Reflections. Oxford: Oxford University Press; 2004. p. 161-177.

Niedzielski, Nancy A.; Preston, Dennis R. Folk Linguistics. Berlin: Mouton de Gruyter; 2003.

Preston, Dennis R. Perceptual Dialectology: Mental Maps of United States Dialects from a Hawaiian Perspective. In: Warkentyne, Henry, editor. Methods IV: Papers from the 4th International Conference on Methods in Dialectology. Victoria, B.C.: University of Victoria; 1981. p. 192-198.

Preston, Dennis R. Whaddayaknow?: The Modes of Folk Linguistic Awareness. Language Awareness. 1996; 5.1:40-74.

Preston, Dennis R., editor. Handbook of Perceptual Dialectology. Vol. 1. Amsterdam: Benjamins; 1999.

Preston, Dennis R.; Howe, George M. Computerized Studies of Mental Dialect Maps. In: Denning, Keith M.; Inkelas, Sharon; McNair-Knox, Faye C.; Rickford, John R., editors. Variation in Language: NWAV-XV at Stanford. Stanford, Calif.: Dept. of Linguistics, Stanford University; 1987. p. 361-378.

Rensink WG. Preston, Dennis R.Informant Classification of Dialects. Mededelingen der centrale commissie voor onderzoek van het nederlandse volkseigen (Amsterdam Dialectbureau Bulletin). 1999; 7(1955):20-23. In Preston 1999, 3-8. Translation of "Dialectindeling Naar Opgaven van Medewerkers,".

Schieffelin, Bambi B.; Woolard, Kathryn A.; Kroskrity, Paul V., editors. Language Ideologies: Practice and Theory. New York: Oxford University Press; 1998.

Sibata, Takesi (柴田武). Consciousness of Language Norms. In: Lawrence, Wayne P., translator; Kunihiro, Tetsuya; Inoue, Fumio; Long, Daniel, editors. Takesi Sibata: Sociolinguistics in Japanese Contexts. Vol. 236. Berlin: Mouton de Gruyter; 1999. p. 371-377.Translation of “ことば の規範意識”『言語生活』(Language Life) 236 (1971): 14-21.

Silverstein, Michael. Language Structure and Linguistic Ideology. In: Clyne, Paul R.; Hanks, William F.; Hofbauer, Carol L., editors. The Elements: A Parasession on Linguistic Units and Levels, April 20-21, 1979, Including Papers from the Conference on Non-Slavic Languages of the USSR, April 18, 1979. Chicago: Chicago Linguistic Society; 1979. p. 193-247.

Tamasi, Susan. Drawing Boundaries: Language Attitudes and the Perception of Place. In: Donaher, Patricia, editor. Barbarians at the Gate: Studies in Language Attitudes. Newcastle upon Tyne: Cambridge Scholars; 2010. p. 116-134.

Wassink, Alicia Beckford; Dyer, Judy. Language Ideology and the Transmission of Phonological Change Changing Indexicality in Two Situations of Language Contact. Journal of English Linguistics. 2004; 32.1:3-30.

Weijnen, Antonius A. On the Value of Subjective Dialect Boundaries. In: Dailey-O'Cain, Jennifer, translator; Weijnen, A.; Renders, JM.; van Ginneken, Jac, editors. Oost-Nordbrabantse Dialectproblemen: Lezingen gehouden voor de dialecten-commissie der Koninklijke Nederlandsche Akademie van Wetenschappen op 12 april 1944. Amsterdam: Noord-Hollandsche Uitgevers Maatschappij; 1999. p. 1-15.In Preston 1999, 131-34. Translation of "De Grenzen Tussen de Oost-Noordbrabantse Dialecten Onderling," 1946.

Wolfram, Walt; Schilling-Estes, Natalie. American English: Dialects and Variation. Malden, Mass: Blackwell; 1998.

Woolard, Kathryn A.; Schieffelin, Bambi B. Language Ideology. Annual Review of Anthropology. 1994; 23:55-82.

\section{Biography}

BETSY E. EVANS is associate professor of linguistics in the Department of Linguistics at the University of Washington. Her research interests focus on the attitudes and perceptions of language variation and the perceptions of spatial distribution of variation in language. 
Most recently, she has worked on incorporating the use of Geographic Information Systems (GIS) for the analysis of perceptual linguistic data. evansbe@u.washington.edu. 
2. Please draw a line around places where you think people's English sounds different.

3. Next, write down what you'd call that way of talking, if you can think of a label for it. Give an example of what's different there (is it a word or pronunciation they use? Or a special way of talking?). Den all osurd alibe.



WASHINGTON

FIGURE 1.

Response from a 25-Year-Old Male from Wenatchee 
2. Please draw a line around places where you think people's English sounds different. NGOME_.

3. Next, write down what you'd call that way of talking, if you can think of a label for it. Give an example of what's different there (is it a word or pronunciation they use? Or a special way of talking?). I dovit find any d. ffem....

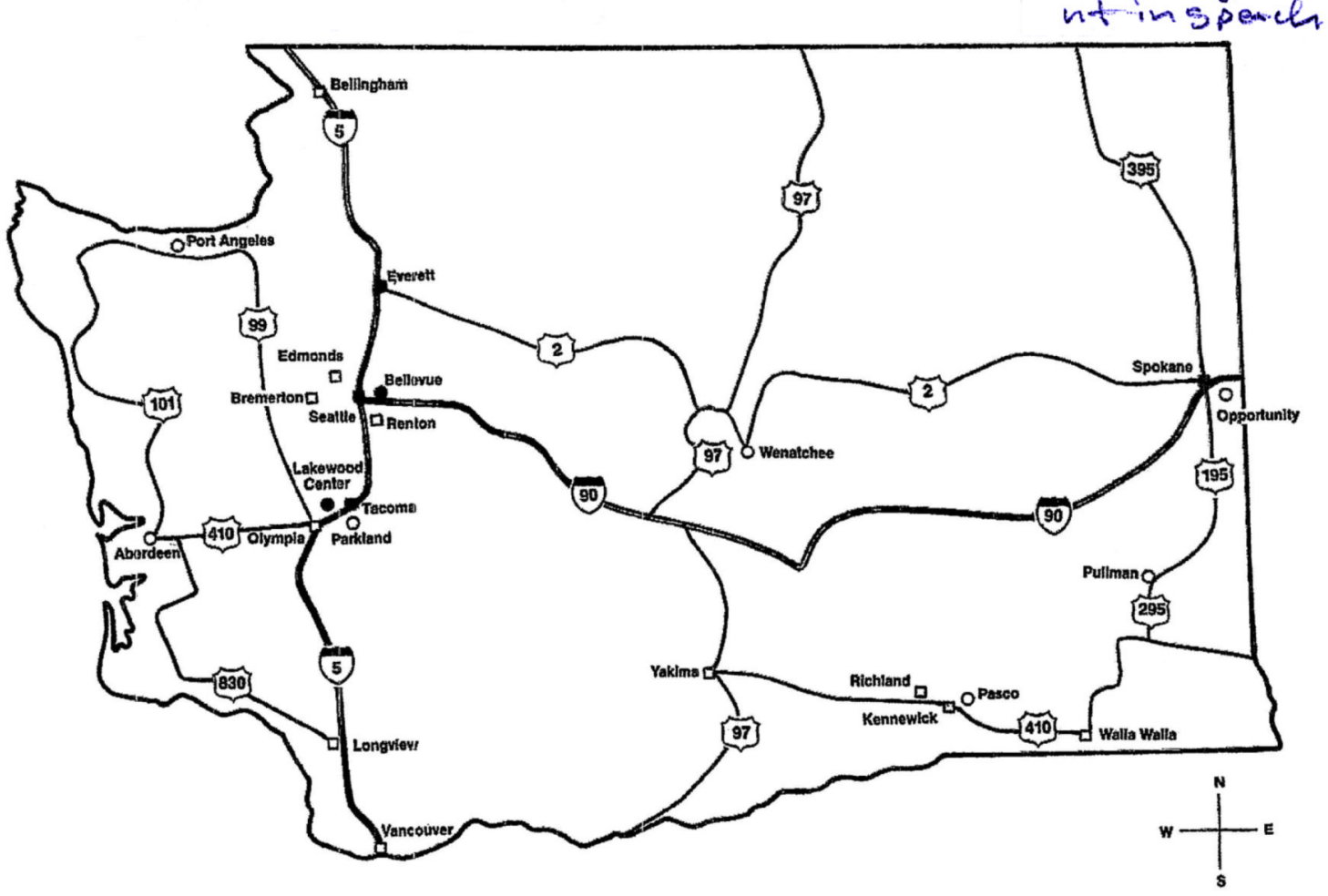

WASHINGTON

FIGURE 2.

Response from a 75-Year-Old Male from Walla Walla 


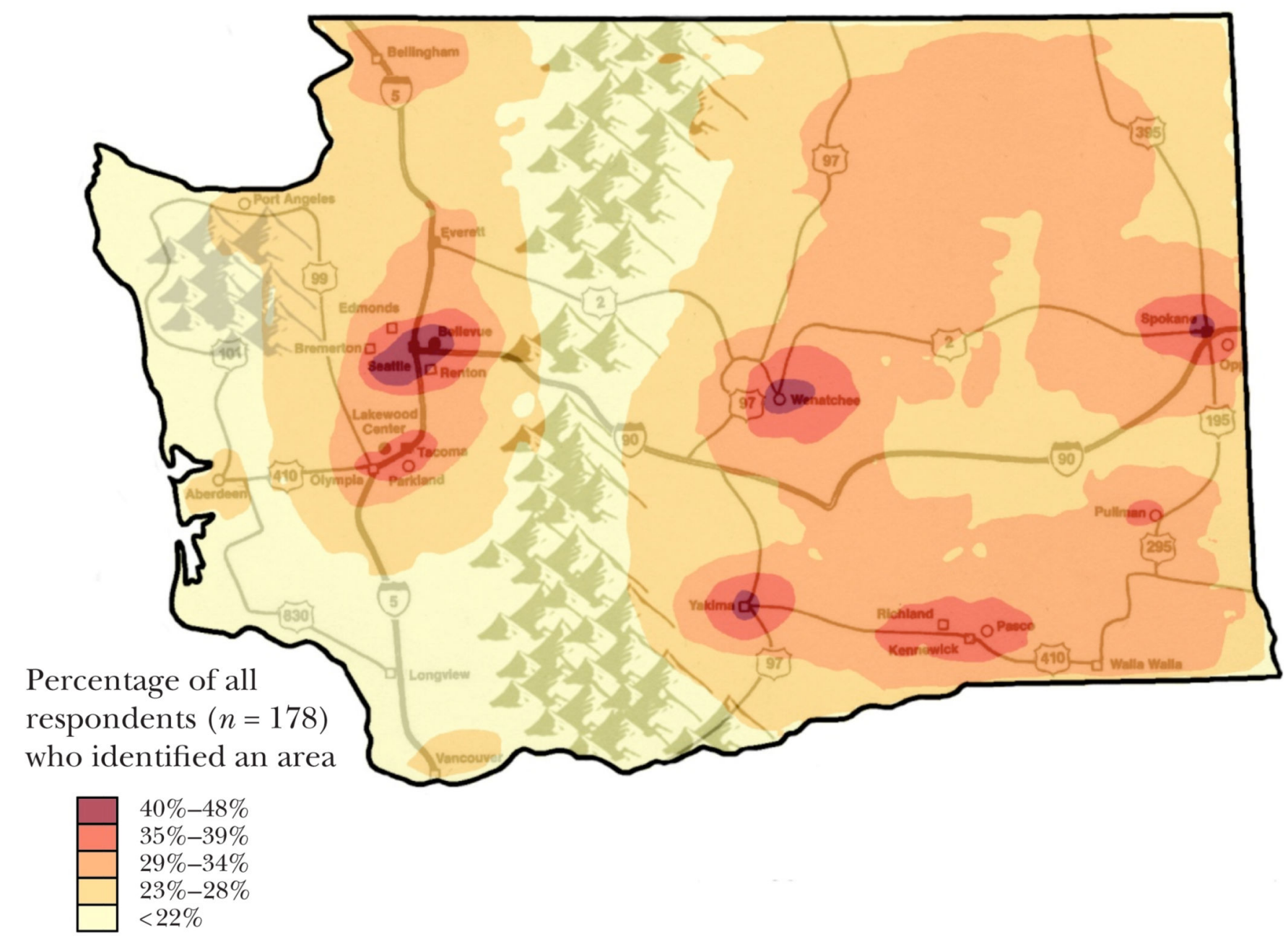

FIGURE 3.

Area Identified by Respondents Who Completed the Map Survey Fully $(n=178$; Evans 2011b) 


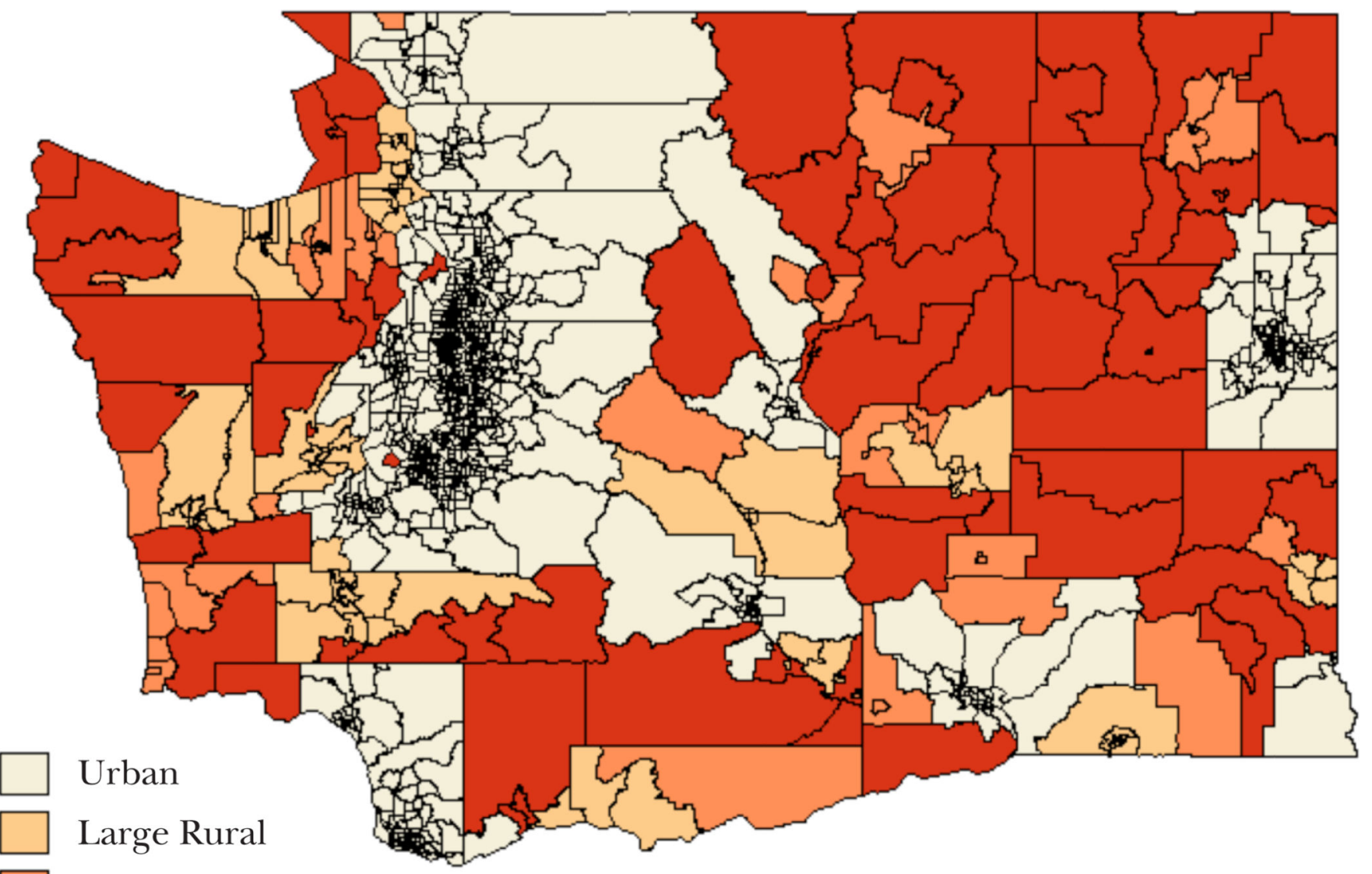

\section{Small Rural}

Isolated

FIGURE 4.

Rural and Urban Areas in Washington According to 2000 U.S. Census Data

NOTE: Map generated using ArcGIS and a data set consisting of 2000 U.S. Census commuting data and 2004 ZIP codes compiled by the WWAMI Rural Health Research Center. Data available at http://depts.washington.edu/uwruca/ruca-data.php. 
TABLE 1

Comments on the Map Survey by Respondents Who Did Not Draw Lines (31 maps with 41 comments)

There is no difference $(n=19)$

"NONE! I don't find any different in [sic] speech East or West" [99]

"Hear no difference" [118]

"Everybody sounds the same to me" [119]

Differences are urban vs. rural $(n=10)$

"As far as standard English I would say that rural English can have more inflection as opposed to city English which is more monotone. Rural English can also take on an embraced Appalachian or Texas sound" [55]

"E Washington tends to have a little more 'twang' to it." [60]

"not specific areas, but more based on city size. People (some, not all) from smaller towns are more relaxed when they speak, while some people from larger cities are more rushed and uptight." [71]

Differences aren't geographic $(n=8)$

"I am having difficulty with this survey because Washington is a rather hodge-podge area when it comes to dialects. I can not differentiate accents based on area, both due to lack of exposure and to an open mind." [87]

"I've never noticed any differences-except Spanish accent, which randomly distributed in Washington [sic]"

"I think most of educated Washington sounds about the same"

I don't know $(n=2)$

"Really have stayed in Seattle most of the time." [34]

"only lived in one town" [162]

Uncategorized $(n=2)$

"Different pronunciation slight accent" [22]

"The year long residents in Pullman tend to talk slower than the rest of Washington." [69] 